\title{
O ESTADO DA ARTE DA APRENDIZAGEM NA EDUCAÇÃO INFANTIL
}

$\underline{\text { Caroline da Silva Ferreira }}^{1}$; Lilian Miranda Bastos Pacheco ${ }^{2}$

1. Bolsista PPPG-UEFS, Graduando em Letras com Espanhol, Universidade Estadual de Feira de Santana, e-mail: caroluefs2013@hotmail.com

2. Orientador, Departamento de Educação, Universidade Estadual de Feira de Santana, e-mail: lilianmpb@gmail.com

PALAVRAS-CHAVE: Educação Infantil, estado da arte, aprendizagem

\section{INTRODUÇÃO}

O presente estudo é fruto do plano de trabalho de iniciação cientifica, cujo tema é Estado da Arte da Aprendizagem na Educação Infantil, o mesmo buscou contribuir com o projeto de Pesquisa "Estado da Arte da Educação Infantil no Brasil de 1990-2003".

$\mathrm{O}$ projeto buscou catalogar e analisar detalhadamente as produções acadêmicas que abordem a temática da Aprendizagem na Educação Infantil, presentes em periódicos internacionais com padrões de excelência na área de Educação, critérios este tomado como base a avaliação QUALIS-CAPES na área de Educação.

A fim de alcançar o objetivo proposto inicialmente foi identificado nos periódicos os artigos científicos publicados que abordem a temática estudada, depois realização da análise das produções encontradas e por fim sistematização dos conhecimentos encontrados.

\section{METODOLOGIA}

Para o andamento dessa pesquisa inicialmente foi empregadas técnicas de pesquisa documental e bibliográfica com o objetivo de construir o conteúdo a ser analisado, para que assim passa haver identificação e compreensão da problemática. A pesquisa do Estado da arte ou Estado do Conhecimento caracteriza-se por ser uma pesquisa com área de conhecimento, tema, suporte textual e período determinado.

Constitui como fontes para a realização desta pesquisa os periódicos internacionais com padrões de excelência na área de Educação, critérios este tomado como base a avaliação QUALIS-CAPES na área de Educação. Os periódicos foram os seis: Cadernos de PesquisaFCC; Educação e Pesquisa - Revista da Faculdade de Educação USP; Educação e RealidadeUFRGS; Educação e Sociedade- CEDES; Revista Brasileira de Educação- ANPED; Investigações em Ensino de Ciências- UFRGS.

Para a identificação dos artigos que abordassem a Educação Infantil foram consultados os periódicos a partir de base de dados virtuais. Depois realizou-se uma pesquisa nestes periódicos por meio dos descritores: creche, pré-escola, educação infantil, 0 a 6 anos, criança, infância e aprendizagem. E posteriormente a catalogação detalhada e a socialização dos conhecimentos apresentados nos artigos.

\section{RESULTADOS E DISCUSSÃO}

As publicações acadêmicas no campo da Educação Infantil no período de 2004 a 2013 presentes nos periódicos analisados totalizam 182 artigos, distribuídos na seguinte ordem: Primeiro temos o Jornal da Fundação Carlos Chagas o Cadernos de Pesquisas que publicou trimestralmente um total de 56 artigos sua preferência é a publicação de estudos empíricos, históricos e / ou documentais. Em segundo lugar, temos a Revista Educação e Sociedade, que integra o Centro de Estudos Educação e Sociedade (CEDES), em suas publicações trimestral publicou 45 artigos. 
Logo após, encontra-se a revista trimestral Educação e Pesquisa que faz parte da Faculdade de Educação da Universidade de São Paulo, com a publicação de 43 artigos, suas investigações possuem caráter teórico ou empírico. Seguindo temos a Revista Brasileira de Educação, seu interesse é na área de educação; educação primária e secundária; ensino superior e políticas educacionais; movimentos sociais e educação, publicou trimestralmente 31 artigos.

Em quantidade bastante inferior aos outros periódicos, encontramos a revista da Educação e Realidade, associada a Universidade Federal do Rio Grande do Sul, classificada pelo Qualis-Capes como revista A1, em suas publicações ininterruptas foi encontrado apenas 4 artigos que tratam o tema da Educação Infantil. Por último, temos a Investigações em Ensino de Ciências (IENCI), que realiza publicações quadrimestral com interesse no ensino/aprendizagem de ciências, possui o total de 3 artigos que abordam o tema da Educação infantil. Conforme a Tabela 1.

Tabela 1: Artigos da Educação Infantil.

\begin{tabular}{|l|c|}
\hline \multicolumn{1}{|c|}{ Periódicos } & Quantidades \\
\hline Cadernos de Pesquisa - FCC & 56 \\
\hline $\begin{array}{l}\text { Educação e Pesquisa - Revista da } \\
\text { Faculdade de Educação da USP }\end{array}$ & 43 \\
\hline Educação \& Realidade - UFRGS & 4 \\
\hline Educação e Sociedade - CEDES & 45 \\
\hline Revista Brasileira de Educação - ANPEd & 31 \\
\hline $\begin{array}{l}\text { Investigações em Ensino de Ciências - } \\
\text { UFRGS }\end{array}$ & 3 \\
\hline Total & 182 \\
\hline
\end{tabular}

Desses 182 artigos que retratam a Educação Infantil, 11 apresentam a temática da aprendizagem. Dentre os artigos encontrados a respeito da aprendizagem: 6 foram no Cadernos de Pesquisas, 3 na Educação e Pesquisa e 2 na Educação e Realidade. Os artigos encontrados foram sistematizados na Tabela 2.

Tabela 2: Artigos sobre Aprendizagem na Educação Infantil por ano de publicação

\begin{tabular}{|c|c|c|c|c|c|c|c|c|}
\hline \multirow[b]{2}{*}{ Periódicos } & \multicolumn{8}{|c|}{ Ano } \\
\hline & ๕̊ & ¿̊̊ & \&̊ํ & \&્స & 윰 & 営 & ำ & $\stackrel{m}{\overbrace{}^{N}}$ \\
\hline Cadernos de Pesquisa - FCC & 1 & 1 & 0 & 1 & 1 & 2 & 0 & 0 \\
\hline $\begin{array}{l}\text { Educação e Pesquisa - Revista da } \\
\text { Faculdade de Educação da USP }\end{array}$ & 0 & 1 & 0 & 0 & 1 & 0 & 1 & 0 \\
\hline Educação \& Realidade - UFRGS & 0 & 0 & 0 & 0 & 0 & 0 & 1 & 1 \\
\hline Total & \multicolumn{8}{|l|}{11} \\
\hline
\end{tabular}

Como se pode perceber na Tabela 2, a temática da Aprendizagem na Educação Infantil começa a ser abordada nos periódicos analisados a partir do ano de 2006, sendo que foram encontrados em maior quantidade nos anos de 2007, 2010, 2011 e 2012, com o total de 2 artigos. No ano de 2008 não foi encontrado publicações em nenhum dos periódicos.

\section{CONSIDERAÇÕES FINAIS}


Diante da coleta realizada por meio da metodologia estado da arte foi possível perceber que a temática da aprendizagem na Educação Infantil possui um número razoável de produções acadêmicas. $\mathrm{O}$ estudo realizado nos artigos encontrados possibilita ao pesquisador uma visão ampla a respeito do tema abordado.

Após o estudo dos artigos encontrado é perceptível que em sua maioria tratam das rotulações presentes na sociedade e na ciência, que colocam fato da criança possuir uma classe menos favorecida ou possuir comprometimentos físicos mentais e/ou sensórias como fatores determinantes do seu fracasso escolar. Como respostas a isso, todos os artigos que abordam esses determinantes mostram que toda criança é capaz de aprender, basta ter acesso a boas experiências de estudo e uma análise com particularidade de cada caso apresentado.

Outro aspecto bastante retratado é a função do docente, ao qual lhe cabe explorar na leitura literária as palavras presentes, possibilitando ao aluno o aumento de seu repertório léxico, ser observador dos estudantes, e a partir disso, poder desenvolver estratégias cognitivas eficientes e conhecer o estilo de aprendizagem de cada educando. Além disso, o professor deve possuir uma boa qualificação, para assim ter uma melhor compreensão do seu papel como educador e possuir mais competência profissional.

Tendo em vista essa quantidade significante de estudos sobre o docente, e ao saber que desenvolvimento da aprendizagem na criança é mediante ao contato com outra criança mais experiente ou adulto e percebendo que as instituições de educação infantil deve ser causador da socialização dessas crianças em ambientes coletivos, em companhia da família. Pode-se dizer que o espaço familiar também possui papel relevante nesse processo de aprendizagem, porém não foi encontrado em nenhum dos artigos analisados pesquisas mostrando como a família pode atuar nesse processo de aprendizagem da criança.

\section{REFERÊNCIAS}

ALMEIDA.T. A.; GOMES. M. F. C.; MONTEIRO. S. M. Aprendizagem e Desenvolvimento de Crianças de Seis Anos na Roda de História. Educação \& Realidade. Porto Alegre, v. 38, n. 4, p. 1303-1326, out./dez. 2013.

AUGUSTO. S. M.; CARDOSO. F. M.; OLIVEIRA. Z. M. R.; SILVA. A. P. S. Construção da Identidade docente: Relatos de educadores de educação infantil. Cadernos de Pesquisa. v. 36, n. 129, set./dez. 20,set./dez. 2006.

BARBOSA. H. H. Uma Nova Estética Escolar: Juntando os aspectos cognitivos e pedagógicos. Educação e Realidade. Porto Alegre, v. 37, n. 3, p. 761-778, set./dez. 2012.

BRASIL. RCNEI - Referencial Curricular Nacional da Educação Infantil - Brasil, Brasília, 1998.

BELITANE.C. Oralidade, alfabetização e leitura: enfrentando diferenças e complexidades na escola pública. Educação e Pesquisa, São Paulo, v.36, n.3, p. 685-703, set./dez. 2010.

BREHER. S. A. S.; PORTILHO. E. M. L. Categorias metacognitivas como subsídio à prática pedagógica. Educação e Pesquisa, São Paulo, v. 38, n. 1, p.181-196, 2012.

EIDT. N. M.; TULESKI.S.C. Transtorno de déficit de atenção/ hiperatividade e psicologia histórico-cultural. Cadernos de Pesquisa, v. 40, n. 139, p.121-146, jan./abr. 2010.

FERREIRA. M. E. C. O enigma da inclusão: das intenções às práticas pedagógicas. Educação e Pesquisa, São Paulo, v.33, n.3, p. 543-560, set./dez. 2007.

FERREIRA. M. C. R.; PAULI. S. C. Construção das dificuldades de aprendizagem em crianças adotadas. Cadernos de Pesquisa, v. 39, n. 138, set./dez. 2009. 
FERREIRA, N. As pesquisas denominadas "Estado da Arte". Educação e Sociedade. Ano XXIII, 79, 257-272, ago. 2002.

KLEINKE. R. C. M. Aprendizagem significativa: A pedagogia por projetos no processo de alfabetização. Florianópolis, 2003.

MELHUISH. E.; SAMMONS. P.; SIRAJ-BLATCHFORD. I.; SYLVA.K.; TAGGART.B. O poder da pré-escola: Evidências de um estudo longitudinal na Inglaterra. Cadenos de Pesquisa v.41 n.142 jan./abri.2011.

MOSS.P. Qual o futuro da relação entre educação infantil e ensino obrigatório? Cadernos de Pesquisas, v.41, n. 142, jan./abri.2011.

SALLES.J. F.; PARENTE. M. A. M. P. Relação entre desempenho infantil em linguagem escrita e percepção do professor. Cadernos de Pesquisa, v. 37, n. 132, set./dez. 20, set./dez. 2007.

SANCHEZ. D. B. S. A psicologia histórico-cultural e a educação infantil. Revista cientifica eletrônica de pedagogia, ano II, n.3, janeiro. 2004.

SANTOS, S. V. S.; SILVA, I. O. Crianças na educação infantil: a escola como lugar de experiência social. Educação e Pesquisa, v. 42, n. 1 p. 131-150, jan./mar. 2016. 